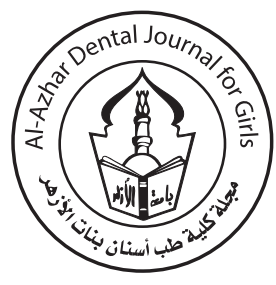

\title{
Evaluation of Intraradicular Surface Roughness Following Final Irrigation by Apple Vinegar and its Correlation with Resin Sealer Bond Strength
}

\author{
Aalaa E. Ali ${ }^{*}$, Mervat I. Fawzy², Hagar A. Bastawy ${ }^{3}$
}

Codex : 11/2001

azhardentj@azhar.edu.eg

http://adjg.journals.ekb.eg

DOI: $10.21608 /$ adjg.2019.7799.1102

\begin{abstract}
Purpose Assessment of the surface roughness of root canal and its correlation with Resin Sealer Bond Strength following final irrigation by apple vinegar. Material and methods 50 extracted lower premolars were selected and prepared using Universal ProTaper rotary files and $14 \mathrm{ml} 2.6 \% \mathrm{NaOCL}$ then the samples were equally distributed into 2 main groups (20 samples each) depending on the type of the final rinse. Group I: Apple vinegar (AV), Group II: 17 \% Ethylenediamine tetra acetic acid (EDTA), Control group (10 samples): sterile saline. Each main group was further equally distributed into 2subgroups (10 samples each). Subgroup A: For surface roughness evaluation. Subgroup B: For push out bond strength evaluation. Surface roughness was evaluated using digital microscope. The push out bond strength test was carried on using universal testing machine. The sealer penetration inside the dentinal tubules was seen under scanning electron microscope (SEM) in selected samples. Results Regarding the results of subgroup A, at all levels, the highest value of the average roughness deviation ( $\mathrm{Ra}$ ) was recorded in samples treated with 17\% EDTA, while the lowest value was recorded with the saline group and there was no statistical significant difference among the tested groups. Regarding the results of subgroup B, at all levels, the highest median push out bond strength was recorded in samples treated with 17\% EDTA, while the lowest value was recorded with the saline group and there was no statistical significant difference among the tested groups except at the apical levels where the difference statistically significant among the tested groups. SEM observation of sealer/ dentin interface revealed few traces of sealer penetration with samples treated with $17 \%$ EDTA and AV. Conclusion EDTA 17\% as a final rinse produced higher value of surface roughness compared to AV. The push out bond strength results of AV was comparable to that of $17 \%$ EDTA when applicated as a final rinse. There is a linear relation between $\mathrm{Ra}$ and the push out bond strength of resin sealer in Groups I, II.
\end{abstract}

\section{KEYWORDS}

Apple vinegar,

irrigating solution,

roughness, AH plus sealer.

- Paper extracted from Master thesis Titled "Evaluation of Intraradicular Surface Roughness Following Final Irrigation by Apple Vinegar and its Correlation with Resin Sealer Bond Strength".

1. Demonstrator of Endodontics, Faculty of Dental Medicine for Girls, Al-Azhar University.

2. Professor of Endodontics, Faculty of Dental Medicine for Girls, Al-Azhar University.

3. Associate Professor of Endodontics, Faculty of Dentistry, King Abdulaziz University (KAU), Jeddah, Saudi Arabia, Faculty of Dental Medicine for Girls, Al-Azhar University, Cairo, Egypt.

* Corresponding author Email: aalaaezzat100@gmail.com 


\section{INTRODUCTION}

Effective treatment of endodontic is pleomorphic. It has been highlighted that chemomecanical preparation of root canals go together to obtain cleaning, shaping and disinfection of canals (1). Irrigation is essential for gross debridement, lubrication, dissolution of tissues, destruction of microrganisms and helps in cleaning areas that are inaccessible for mechanical cleansing. Apart from beneficial effects, irrigants may exhibit detrimental effects on the dentin or root canal filling materials ${ }^{(2)}$.

Irrigating solutions have important role in endodontic treatment and allow topographical differences in dentin surface ${ }^{(3)}$. Chelating agents during root canals preparation have the ability of smear layer (SL) removal, so the amount of the irrigant that enter the dentinal tubules increased for adequate disinfection ${ }^{(4)}$. Chelating agents such as Ethylenediamine tetra acetic acid (EDTA) and natural products as apple vinegar are available.

The most popular root canal irrigant currently used is $\mathrm{NaOCl}$. Its popularity is due to its tissue dissolving along with being antimicrobial and potent lubricant. The high $\mathrm{pH}$ of $\mathrm{NaOCl}$ interferes biosynthesis alteration in celluar metabolism, and phospholipids degradation ${ }^{(5)}$. Ethylenediamine tetra acetic acid (EDTA) is the most irrigant used for removal of SL and cleaning the root canals. Nevertheless, EDTA is considered a pollutant (6). It has a harmful effect on periapical tissues. Moreover, EDTA is not originally present in nature so, the researches for EDTA replacement is essential ${ }^{(7)}$. Apple vinegar has capability for smear layer removal from the dentinal surfaces. The high percentage of malic acid (MA) in the composition of $\mathrm{AV}$ is responsible for its high biocompatibility ${ }^{(8)}$.

The advantage of surface roughness is the micromechanical interlocking of dental materials to obtain the adhesion of root canal sealers ${ }^{(9)}$. Dental Gutta-percha (GP) is a standard root canal filling material. The use of epoxy resin-based sealer produced high bond strength to dentine Nevertheless, it has an improper adhesion to root dentin. Among the advantages of root canal sealers is to do a bonded interface between the core filling material and root dentin. The use of epoxy resin-based sealer produced high bond strength to dentine. It showed clinical acceptable physicochemical properties ${ }^{(10) .}$

SEM study evaluated the chelating effect of apple vinegar (as a natural irrigant) in comparison with other irrigants at the three levels of root canal (coronal, middle and apical) after mechanical instrumentation. The results concluded that $\mathrm{AV}$ was promising in elimination of the smear layer as $17 \%$ EDTA. These results suggested that AV is a promising chelating agent ${ }^{(11)}$.

Several techniques, such as stylus profilometer, optical profilometer and SEM can be utilized to assess the surface roughness. The advantages in changing the root canal dentin's roughness is the increased area of dentin surface designed for endodontic sealers adhesion ${ }^{(12)}$. Even so, excessive extension of this area could be adopted by voids formation, which compromises the interface and so decreasing adhesion ${ }^{(13)}$.

Push-out bond strength tests, tensile tests, and shear tests, can be assessed to survey the bond strength of materials to dentin. The push-out test is reportedly practical ${ }^{(14)}$.Therefore, this research aim was directed to determine the correlation between surface roughness of root canal surface and adhesive sealer following final irrigation by apple vinegar through assessing the surface roughness of root canal and evaluating the bond strength of adhesive sealer to root canal surface using push-out bond strength test.

\section{MATERIAL AND METHODS}

\section{Teeth selection and preparation}

50 recently extracted human single rooted lower premolars with single canal, completely formed roots and no evidence of fractures or cracks were selected. The teeth were cleaned under tap water 
to remove tissues, blood and debris then kept until use in sterile saline. Each tooth was decapitated at the cemento-enamel junction (CEJ) by diamond disc (Diatech, GoltèneAG, Altstätten, Switzerland) under steady water cooling. The root length of all samples was fifteen mm. Canal patency was done by \#10 K-files (MANI Inc., Japan) and the working length measurement was adjusted by decreasing $1 \mathrm{~mm}$ from length when the tips of \#10 K-file became observed at the apical foramen.

ProTaper Universal rotary NiTi files (Dentsply, Maillfer, Switzerland) were used in a crown-down manner for root canal preparation with torque and speed adjusted according to manufacturers' recommendations for each file used. A set of seven instruments were used (SX, S1, S2, F1, F2, F3and F4), the first three files were used for coronal $2 / 3$ preparation and the other four files were used for apical preparation. After each instrument use, irrigation was done with a fresh preparation of 2 $\mathrm{ml} 2.6 \% \mathrm{NaOCl}$ solution for 1 minute dispensed through a 30-gauge side vent-irrigating needle, where the needle was inserted deeply inside the root canal without binding.

\section{Samples grouping:}

After preparation of root canal, the samples were equally distributed into two experimental groups (I, II) (20 samples each) according to the final rinse used and control group (10 samples). Group I: Samples were irrigated with apple vinegar (commercial). Group II: Samples were irrigated with 17\% EDTA (Prevest Denpro limited, Digiana, Jammu, India). Control group: samples were irrigated with sterile saline (MottAHedoonpharma, Egypt), each group was irrigated using $5 \mathrm{ml}$ of the irrigant for 1 minutes. Then all samples were received $5 \mathrm{ml}$ of distilled water for final rinsing and became dry with utilizing paper points. Each group was further equally distributed into two subgroups; subgroup A: Surface roughness was evaluated using digital microscope and subgroup B: samples were filled with gutta-percha/AH Plus sealer (Dentsply
DeTrey, Konstanz, Germany) and tested for push out bond strength.

\section{Samples preparation}

\section{Surface roughness testing, subgroup A ( IA, IIA and control A) :}

Samples were prepared from root halves of single rooted mandibular premolars as each root were separated longitudinally in buccolingual direction to show the entire canal extension. They were cleaned from dentin chips of cutting by using soft brush and distilled water. The best half of each root was embedded in acrylic resin. Three points of different positions on the root canal lumen dentin were evaluated. The average roughness deviation (Ra) was determined using digital microscope.

\section{Push-out bond strength testing, subgroup B (IB, IIB and control $B)$ :}

The samples were filled with ProTaper guttapercha cones (\#F4) and AH Plus sealer which was manipulated according to manufacturers' instructions. The canal walls were covered with sealer where, the sealer was added on the master cone which moved vertically up and down inside the canal to coat the canal wall completely by the sealer. Root canal filling was done using cold lateral compaction technique using \#25 finger spreader and adding accessory cones (\#25, 0.02 taper). The excess gutta-percha was seared off using hot instrument, then this access cavity was filled with a non-permanent filling.

All samples were put at $37^{\circ} \mathrm{C}$ in $100 \%$ dampness for a weak to guarantee full setting of the sealer. Isomet 4000 microsaw (Buehler, USA) was used to section the samples perpendicular to the root's long axis without water coolant, where three $2 \mathrm{~mm}$ thickness sections were gained from coronal, middle and apical levels of each sample. Indelible marker was used to mark the apical surface of each section, and then the sections were kept in $100 \%$ humidity until testing. 
Cylindrical stainless-steel plungers with diameter $0.9,0.7$ and $0.5 \mathrm{~m}$ corresponding to coronal, middle and apical sections respectively were used to load root filling of each section. The tip of the plunger was adjusted to cover the root filling material without contacting the wall of canal. The plunger was connected to the universal testing machine (Instron, Norwood, MA, USA) and the applied load was directed from apical aspect to coronal aspect in order to avoid any impediments during the pushout testing because of tapering of the root canal. A cross-head speed of $0.5 \mathrm{~mm} / \mathrm{min}$ was conducted until debonding happened and the maximum load conducted for debonding was measured in Newton $(\mathrm{N})$

The push out bond strength value in mega-pascal (MPa) for each sample was calculated using the following equation:

\section{Push-out bond strength $(M P a)=$}

Maximum load (N)

Adhesion area of root canal filling ( $\mathrm{mm} 2)$

Area of root canal filling $\left(\mathrm{mm}^{2}\right)=$

$\{($ Circumference of coronal aspect + circumference of apical aspect) $\mathrm{x}$ thickness of the section\}

\section{2}

\section{SEM evaluation:}

After the push-out test, three selected sections from each subgroup (I B, II B and control B) were grooved longitudinally in buccolingual direction without reaching the internal portion of the canal and sectioned with sharp chisel. The sections were coated with gold and examined under SEM (FEI company, Nertherland). Under magnifications (X 2000and X 4000), two photomicrographs were obtained to show the amount of sealer penetration in the dentinal tubules.

\section{Statistical analysis:}

Surface roughness data showed normal (para- metric) distribution while push-out bond strength data represented non-normal (non-parametric) distribution. For parametric data; Repeated measures ANOVA test was used to study the effect of irrigant, root level and their interactions on mean surface roughness. Bonferroni's post-hoc test was used for pair-wise comparisons when ANOVA test was significant. For non-parametric data; Kruskal-Wallis test was used to compare between the three irrigants. Friedman's test was used to compare between the different root levels. Dunn's test was used for pair-wise comparisons.

Thesignificancelevel was setat $P \leq 0.05$. Statistical analysis was done with IBM ${ }^{\circledR}$ SPSS ${ }^{\circledR}$ Statistics Version 20 for Windows.

\section{RESULTS}

\section{Surface roughness results:}

\section{Subgroup A: Table 1}

\section{Comparison of surface roughness between the tested chelating agents at each root level:}

The difference among the tested irrigants was not statistically significant $(\mathrm{P}>0.05)$

\section{Comparison of surface roughness among the root levels within each group:}

At all root levels (coronal, middle and apical) the difference among the tested irrigants was not statistically significant $(\mathrm{P}>0.05)$

\section{Push out bond strength test results:}

Subgroup B: ( Fig. 1)

\section{Comparison of bond strength between the tested chelating agents at each root level:}

At all root levels (coronal, middle and apical), the difference among the tested irrigants was not statistically significant $(\mathrm{P}>0.05)$ 
Table (1): The mean value and standard deviation (SD) for comparison between the tested chelating agents and control group within subgroup A at the coronal, middle and apical root canal levels

\begin{tabular}{|c|c|c|c|c|}
\hline \multirow{2}{*}{ Root level } & Group I (AV) & GroupII (17\%EDTA) & Control & \multirow{2}{*}{ P-value } \\
\cline { 2 - 5 } & Mean \pm SD & Mean \pm SD & Mean \pm SD & 0.393 \\
\hline Apical & $0.2518 \pm 0.0154$ & $0.2573 \pm 0.0050$ & $0.2411 \pm 0.0429$ & 0.6625 \\
\hline Middle & $0.2543 \pm 0.0401$ & $0.2576 \pm 0.0367$ & $0.2445 \pm 0.0194$ & 0.3562 \\
\hline Coronal & $0.2560 \pm 0.0036$ & $0.2581 \pm 0.0024$ & $0.2504 \pm 0.0206$ & $0.0284 *$ \\
\hline Total & $0.254 \pm 0.014$ & $0.2574 \pm 0.0032$ & $0.245 \pm 0.009$ & \multirow{2}{*}{} \\
\hline
\end{tabular}

*: Significant at $P \leq 0.05$

\section{Comparison of push out bond strength among} the root levels within each group:

In group II (17\% EDTA), the difference among the three root levels was statistically significant in apical third ( $\mathrm{P} \leq 0.05)$. While in group $\mathbf{I}(\mathrm{AV})$ and control group (normal saline), the difference was not statistically significant $(\mathrm{P}>0.05)$.

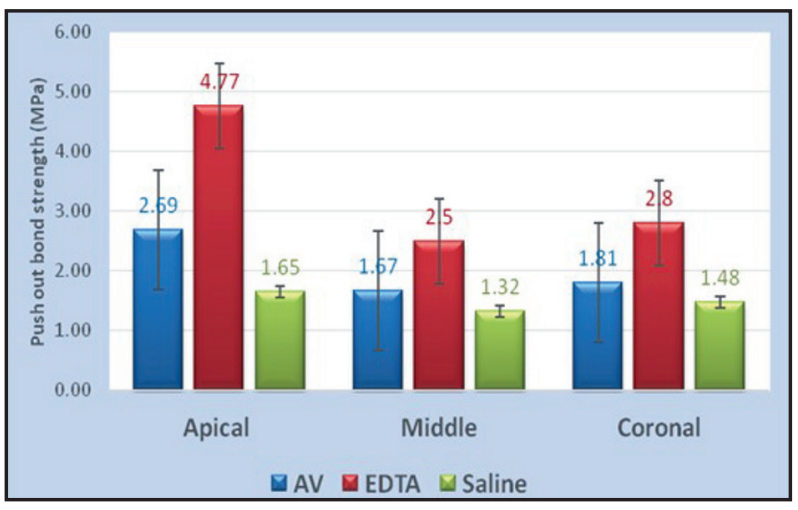

Figure (1) A bar chart comparing the mean value and SD of push out bond strength among 17\% EDTA, AV and normal saline (control) within subgroup B at the apical, middle and coronal root canal levels.

\section{Correlation between surface roughness and push-out bond strength}

There was no statistically significant correlation between surface roughness ( $\mathrm{Ra})$ and push-out bond strength (Correlation coefficient $=0.229, \mathrm{P}$-value $=$
0.270).There is a linear relation between $\mathrm{Ra}$ and the push out bond strength (Fig. 2).

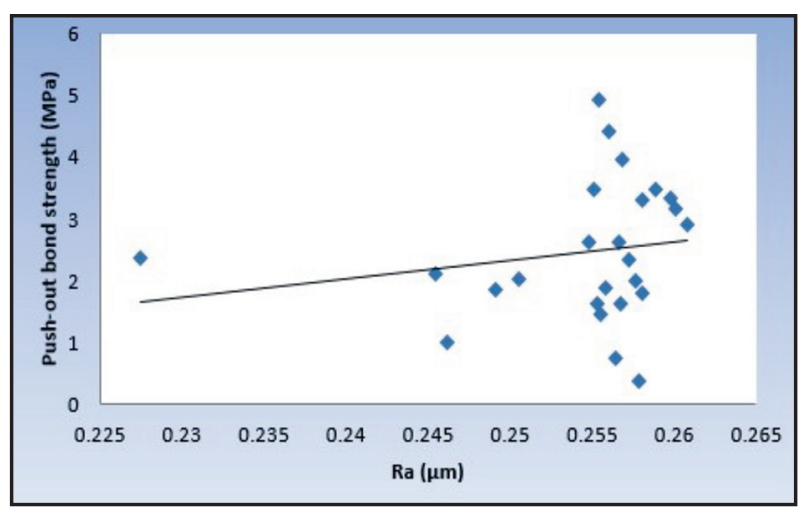

Figure (2) Scatter diagram representing direct correlation between surface roughness and push-out bond strength

\section{Scanning electron microscopic results:}

\section{Group I (AV):}

Tracing the interface revealed that few traces of sealer particles penetrating dentinal tubules at coronal, middle and apical levels. (Fig. 3).

\section{Group II (17\% EDTA):}

Tracing the interface revealed that many traces of sealer particles penetrating dentinal tubules at three levels especially at coronal and middle levels. (Fig. 4) 


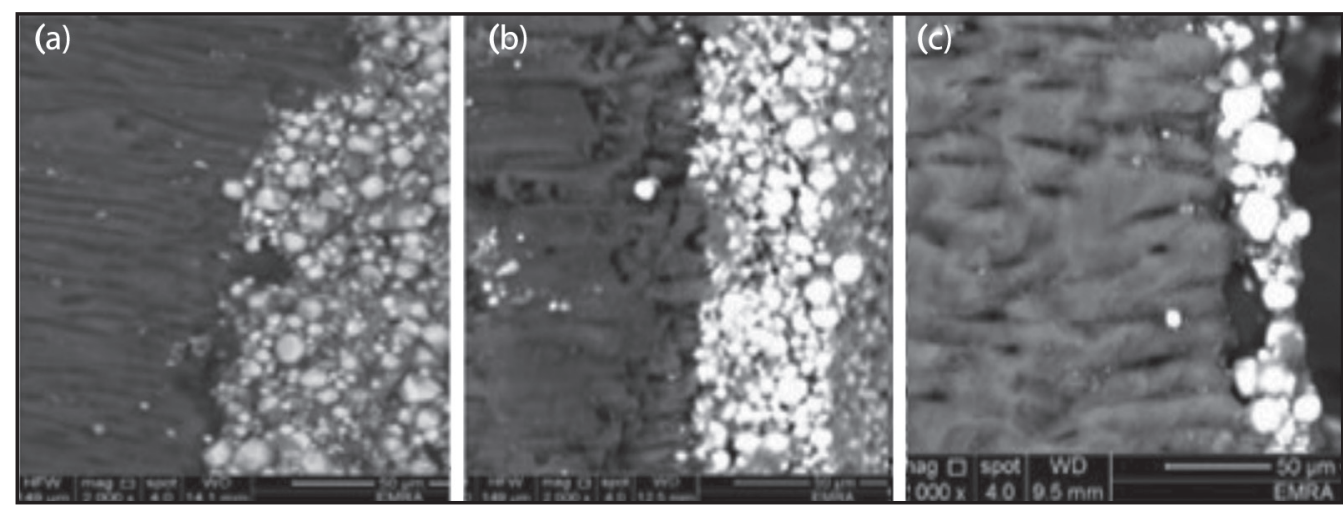

Figure (3) A scanning photomicrograph of sealer/dentin interface at the a: coronal, $\mathbf{b}$. middle and $\mathbf{c}$ : apical levels of samples rinsed with AV (X2000)

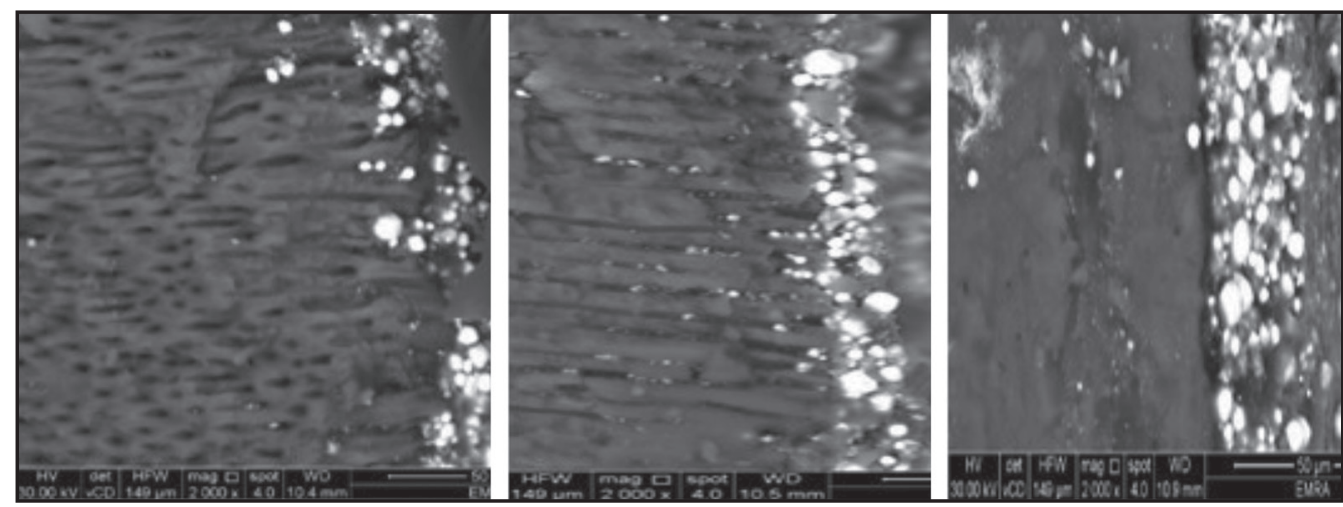

Figure (4) A scanning photomicrograph of sealer/dentin interface at the a: coronal, b. middle and c: apical levels of samples rinsed with 17\% EDTA (X2000).

\section{DISCUSSION}

Dentin of root canal might be affected by irrigation solutions, including roughness, microhardness, wettability and solubility. Increasing the surface roughness has advantage as it may increase the micro-mechanical adhesion of root canal sealers, which requires irregularities on the surface of the adherent for penetration ${ }^{(15)}$. Nevertheless, too much irregularities can assist in bacterial adhesion, which might lead to decrease durability due to voids formation that affect sealer penetration ${ }^{(16)}$.

Due to the cytotoxic reactions of the almost all of the commercial intracanal medicaments used, tendency to use biologic medication extracted from natural plants is essential ${ }^{(17)}$.

Accordingly, apple vinegar was used in this study because of its antibacterial action, and its efficacy in the removal of smear layer ${ }^{(18)}$.
Using new irrigating solutions must be firstly tried with in-vitro studies which evaluate the beneficial effects and sequela on human beings .Therefore, the target of the on going study was directed to determine the correlation between surface roughness of root canal surface and adhesive sealer $(\mathrm{AH}$ plus) .

The current study was performed on single rooted extracted premolars, where their crowns were decapitated at the cemento-enamel junction that allows samples standardization and to avoid the human variable that could be related to the coronal access cavity preparation.

ProTaper Universal rotary files were used for canals instrumentation, as they have a convex triangular cross-section, which decreases the friction between the blade of file and the canal wall and increases its cutting efficiency. Moreover, 
there design enhances its cutting action, effectively allows its blades to remove debris out of the canal, and importantly prevents the instruments from inadvertently screwing into the canal. Apical preparation of the canals was ended with F4 ProTaper Universal file to ensure complete cleaning and shaping of the root canal. In addition, ProTaper gutta-percha perfectly fit canals that have been prepared with ProTaper files, which minimizes the volume of the sealer used and, thus, the sealing quality could be improved ${ }^{(19)}$

In the present study, a volume of $5 \mathrm{ml}$ of $\mathrm{AV}$ and $17 \%$ EDTA were used as final rinse for 1 minutes in groups I and II, as it has been reported that they are effective in removing the smear layer. Final rinse was done for 1 minute for all the irrigation groups, as it has been reported that use of EDTA longer than 1 minute causes erosion ${ }^{(20)}$ and greater demineralizing effect on the dentin.

In this study, AH plus sealer was used because it is an epoxy resin-based sealer which form covalent bonds with root dentin due to opening of its epoxide ring that has no photo polymerization system in its composition, thus undergoing homogeneous polymerization with high bond strength. In addition, the chemical polymerization is a slow process which allows for adequate shrinkage stress relaxation in AH Plus sealer ${ }^{(21)}$.

The obturation of the samples was performed using lateral compaction technique due to its ability to allow more control during the filling procedure where the resin was pressed into the dentinal tubules and into irregularities in the canal walls, producing a tight contact with the surface dentin ${ }^{(22)}$. Bond strength testing is the most common method for determining the effectiveness of adhesion between endodontic materials and tooth structure. Push out bond strength testing was used in the current study because it is easy to align samples for testing and accurate. The use of 2-mm thick samples eliminated the probability of non-uniform stress distribution ${ }^{(23)}$.
Surface roughness in the present study was measured by digital microscope that is one of non-contact optical profilometrs as it is capable of measuring an area from the surface rather than a single line producing 3D measurements which can calculate volumes of bumps or voids and large field of view offers more surface information ${ }^{(24)}$. It is important to know the threshold of the amount of roughness. Irregularities, which may help in bonding procedure, are in a very smaller scale than wide-ranging waviness of the surface ${ }^{(25)}$.

$\mathrm{NaOCl} 2.6 \%$ was used in the current study during instrumentation that increases its permeability to the effect of the chelating agents, resulting in increased surface roughness ${ }^{(26)}$. Final rinsing with EDTA resulted in higher Ra values compared to AV and saline without significant difference as EDTA enhances more efficiently the smear layer removal in the root canal compared to $\mathrm{AV}{ }^{(27)}$.

In the current study, the results are comparable to that obtained with previous study, in which EDTA produced higher $\mathrm{Ra}$ than saline due to its higher chelating effect ${ }^{(28)}$.

The Surface roughness (subgroup A) increased from apical to coronal (groups I, II and control) without significant difference. The highest value was recorded at the coronal third which probably due to the flute size increased from the apical section of the file towards the coronal ${ }^{(25)}$. However, the results of this study disagree with the previous one which showed the least homogenous was the apical third and the smoothest one was the coronal. This probably due to the use of different instruments and evaluation methods ${ }^{(29)}$

The higher significant difference of bond strength results of gutta-percha and AH Plus sealer recorded with the use of 17\% EDTA compared to AV group. These results could be attributed to the higher demineralization effect of EDTA which expose more collagen, where the adhesion of $\mathrm{AH}$ plus sealer to dentin depends on bonding between the open epoxy rings in the sealer with 
the exposed amine groups on collagen (organic part of the dentin) forming a covalent bond, rather than micromechanical retention through the resin tags penetration into the tubule ${ }^{(30)}$. The results are comparable to what has been reported previously that AV produced lower push out bond strength results due to its lower efficiency in smear layer removal than EDTA ${ }^{(31)}$. The lowest push out bond strength results recorded with normal saline are in agreement with another study stated that the use of chelating solutions enhanced the bond strength of AH Plus sealer ${ }^{(32)}$.

The highest bond strength results of gutta-percha and $\mathrm{AH}$ plus sealer was recorded at the apical level irrespective to the final rinse used that is in agreement with the previous study. These results could be due to the circular cross-section of root canal at apical third that provided higher resistance to dislodgment forces during the testing. On the other hand, coronal and middle portion has oval or even flattened root canal sections. These variations in the anatomy of root canal might lead to improper fit of the main gutta-percha and lead to impaired bond strength ${ }^{(33)}$.

The results in this study disagree with the other study, which showed the highest bond strength at the coronal level irrespective to the final rinse used ${ }^{(34)}$. This probably due to the use of different obturating materials and irrigating solutions.

In the present study, SEM observation of sealer/ dentin interface of tested samples which were treated with 17\% EDTA and AV revealed that there was few traces of sealer penetrating into the dentinal tubules. This may be attributed to 17\% EDTA and AV could penetrate into dentinal tubules removing smear plugs, and thus permitting the penetration of the sealers. Coronal third reveled more penetration then the middle third, and least one in the apical third. This difference in sealer penetration could be due to the presence of significantly more density of dentinal tubules with greater diameter at the coronal and middle third, as compared to the apical one (35). Samples treated with normal saline showed no sealer penetration.

\section{CONCLUSIONS}

- EDTA $17 \%$ as a final rinse produced higher value of surface roughness compared to AV.

- The push out bond strength results of AV was comparable to that of $17 \%$ EDTA when used as a final rinse.

- There is a linear relation between $\mathrm{Ra}$ and the push out bond strength of resin sealer in Groups I, II.

\section{REFERENCES}

1. Akcay I, Sen BH. The effect of surfactant addition to EDTA on microhardness of root dentin. J Endod 2012; 38:704- 7 .

2. Bhagwat SA, Lopez TA, Mandke LP. Comparison of the effect of ethylene diamine tetra-acetic acid, chlorhexidine, etidronic acid and propolis as an irrigant on the microhardness of root dentin :( An in vitro study). J Dent Res 2016; 3:23-30.

3. Oliveira J, Neto W, Faria N, FernandesF, Miranda C, AbiRached F. Quantitative assessment of root canal roughness with calcium-based hypochlorite irritants by $3 \mathrm{D}$ CLSM. Braz Dent J 2014; 25: 409-15.

4. Cruz-Filho AM, Sousa-Neto MD, Savioli RN, Silva RG, Vansan LP, Pécora JD. Effect of chelating solutions on the microhardness of root canal lumen dentin. Int Endod J 2011; 37: 358-62.

5. Frazaneh S, Pariokh M, Nakhaee N, Abbott PV. Effect of two different concentrations of sodium hypochorite on postoperative pain following single-visit root canal treatment: a triple-blind randomized clinical trial. Int Endod J 2018; 51: 9- 11 .

6. Crumpton BJ, Goodell GG, Clanahan SB. Effects on smear layer and debris removal with varying volumes of 17\% REDTA after rotary instrumentation. J Endod 2005; 31: 536-8.

7. Spanó JCE, Silva RG, Guedes DFC, Sousa-Neto MD, Estrela C. Atomic absorption spectometry and scanning electron microscopy evaluation of concentration of calcium ions and smear layer removal with root canal chelators. J Endod 2009; 35: 727-30.

8. Caligiani A, Acquotti D, Palla G, BocchiV. Identification and quantification of the main organic components of 
vinegars by high resolution $1 \mathrm{H}$ NMR spectroscopy. Anal Chim Act 2007; 585:110-9.

9. Tartari T, Junior AP, Klautau KB, Sousa MH, Patrícia DE. Effects of different irrigation regimes on root dentin roughness. J Appl Oral Sci 2013; 21:409-15.

10. Babb BR, Loushine RJ, Bryan TE, Ames JM, Causey MS, Kim J, et al. Bonding of Self- adhesive (Self-etching) Root Canal Sealers to Radicular Dentin. J Endod 2009; 35 : 578-82.

11. Safwat H, Nour El Din M, Bastawy H. Evaluation of the effect of Apple vinegar on smear layer removal. Al-Azhar dent. J for girls 2017; 3:279-87

12. Estrela C, Estrela CR, Barbin EL, Spano JC, Marchesan MA, Pecora JD. Mechanism of action of sodium hypochlorite. Braz Dent J 2002; 13:113-7.

13. Kokkas AB, BoutsioukisACh, Vassiliadis LP, Stavrianos CK. The influence of the smear layer on dentinal tubule penetration depth by three different root canal sealers: an in vitro study. J Endod 2004; 30:100-2.

14. Goracci C, Tavares AU, Fabianelli A, Monticelli F, Raffaelli O, Cardoso PC, et al. The adhesion between fiber posts and root canal walls: Comparison between microtensile and push-out bond strength measurements. Eur J Oral Sci 2004; 112:353-61.

15. Hu X, Ling J, Gao Y. Effects of irrigation solutions on dentin wettability and roughness. J Endod 2010; 36:1064-7.

16. Kokkas AB, Boutsioukis ACh, Vassiliadis LP, Stavrianos CK. The influence of the smear layer on dentinal tubule penetration depth by three different root canal sealers: an in vitro study. J Endod 2004; 30:100-2.

17. Palombo EA. Traditional medicinal plant extracts and natural products with activity against oral bacteria; potential application in prevention and treatment of oral diseases. Evid Based Complement Alternat Med 2011; 680354:15

18. Budak NH, Aykin E, Seydim AC, Greene AK, Guzel ZB Functional properties of Vinegar J. Food 2014; 79:757-64.

19. Ruddle CJ. The ProTaper technique. Endod Topics. 2005; 10:187- 90

20. Calt S, Serper A. Time dependent effects of EDTA on dentin structures. J Endod 2002; 28:17-9.

21. Hegde V, Arora S. Fracture resistance of roots obturated with novel hydrophilic obturation systems. J Conserv Dent 2015; 18: 261- 4 .
22. Ahlberg KM, Tay WM. A methacrylate-based cement used as a root canal sealer. Int Endod J. 1998; 31:15-21.

23. Goracci C, Tavares AU, Fabianelli A, Monticelli F, Raffaelli O, Cardoso PC, et al. The adhesion between fiber posts and root canal walls: Comparison between microtensile and push-out bond strength measurements. Eur J Oral Sci 2004; 112:353-61.

24. Srinivas N, Srilakshmi E, Subba R. Measurements with 3D Non-contact optical profilometry . J of Eng and Tech $2015 ; 1: 41-45$

25. Vahid SM. Quantitative evaluation of root canal surface roughness after filing with adaptive reciprocating and continuous rotary instruments. Microsc Res Tech 2017; 80:657-61.

26. Ring KC, Murray PE, Namerow KN, Kuttler S, GarciaGodoy F. The comparison of the effect of endodontic irrigation on cell adherence to root canal dentin. J Endod 2008; 34:1474-9.

27. Alison L, Kirchhoffl AL, Viapiana R, Miranda CES, Sousa Neto MD, Cruz F. Comparison of apple vinegar with other chelating solutions on smear layer and calcium ions removal from the root canal. Ind dent res 2014; 3: 370-4.

28. Ballal NV, Khandewal D, Karthikeyan S, Somayaji K, Foschi F. Evaluation of Chlorine Dioxide Irrigation Solution on the Microhardness and Surface Roughness of Root Canal Dentin. Eur J Prosthodont Restor Dent 2015 Dec; 23:173-8

29. Foschi F, Nucci C, Montebugnoli L, Marchionni S, Breschi L, Malagnino VA, Prati C. SEM evaluation of canal wall dentine following use of Mtwo and ProTaper NiTi rotary instruments. Int Endod J 2004; 37:832-9.

30. Neelakantan P, Varughese AA, Sharma S, Subbarao CV, Zehnder M. Continuous chelation irrigation improves the adhesion of epoxy resin-based root canal sealer to root dentin. Int Endod J 2012; 45:1097-102.

31. Salah M, Nour El Din M, Bastawy H. Evaluation of the Effect of Endodontic Chelating Solutions on push Out Bond Strength of Endodontic Sealers. M.S.C Faculty of dental medicine for girls. Al-Azhar Unversity 2017; 25-6

32. Verma D, Taneja S, Kumari M. Efficacy of different irrigation regimes on the push-out bond strength of various resin-based sealers at different root levels: An in vitro study. J Conserv Dent 2018; 21:125-9. 
33. Baldissera R, Rosa RA, Wagner MH, Kuga MC, Grecca FS, Bodanezi A, et al. Adhesion of real seal to human root dentin treated with different solutions. Braz Dent J 2012; 23:521-6.

34. Farag W, Etman H, AlhadainyA,.Darrag . Effect of different irrigating protocols on push out bond strength of
Resilon/Epiphany obturation system.Tanta Dent. J 2015; 4: $241-8$

35. Canderio GTM, Matos IB, Costa CFE, Fonteles CSR, Vale MS. A comparative scanning electron microscopy evaluation of smear layer removal with apple vinegar and sodium hypochlorite associated with EDTA. J Appl Oral Sci 2011; 19:639-43. 